\title{
A Comprehensive Study of PV Array Connection Strategy with effect of Temperature to Improve System Efficiency
}

\author{
Neha Ghei ${ }^{1}$, Bharat Modi ${ }^{1}$, Mahendra Lalwani ${ }^{2}$ \\ ${ }^{1}$ Department of Electrical Engineering, Swami Keshvanand Institute of Technology, Management \& \\ Gramothan, Jaipur-302017 (INDIA) \\ ${ }^{2}$ Department of Electrical Engineering, Rajasthan Technical University Kota-302050 (INDIA) \\ Email: neha.ghei22@email.com, bharatalone@gmail.com, mlalwani@rtu.ac.in \\ Received 21.01.2021, received in revised form 04.05.2021, accepted 04.05.2021
}

\begin{abstract}
The temperature at which the PV array functions acts as a pivotal role in the PV (photovoltaic) energy transformation process. Efficiency and Output of a PV Array do not deviate from operating temperature. Photo Voltaic cell or PV cell exhibits a different behaviour with a slight increase in temperature, accountable for the surge in internal carrier recombination rate, as carrier concentrations increased by a length. Numerous interdependent relationships suggested in composition depict clarification for equations which can be claimed for installation of PV Arrays, free-standing structures, PV thermal Collectors to building-integrated PV Arrays, respectively.
\end{abstract}

Keywords- PV, RES, DC, PVG, NPC inverter

\section{INTRODUCTION}

Renewable energy sources (RES) offer an unconventional solution to a new Era where energy demand continues to grow, and also due to the location of load in the remote areas. An extreme requirement of an unconventional source of energy is quested for electrical power supply till now, Conventional sources of energy like fossil fuels were used but Energy demand in the world is rising day by day which cannot be accomplished only by the fuel sources. Thus, these days, on the above subject renewable energy sources is an excellent solution. [1-5]

A mix of ecological mindfulness, advancing monetary and international strategies, and general assessment for issues like Energy crises have driven the world of Research to connect effectively and create financing for the promotion of RES on a different level then the past decade of prior efforts, Far-reaching concerns in the academicians, civil servants, and public, at large is additionally determined for research and growth of unconventional source of energy from RES. [6-7] RES includes several technological fields according to the source of energy used and generation of energy. In this paper PV solar cell is studied. PV (Photovoltaic) energy is considered the most attractive source of energy among the other types of renewable energy sources (RES). Electrical energy is created by PV Array when solar radiation is transformed to DC with the help of electromechanical transformation. that is, into direct current by use of semiconductor materials made of monocrystalline, polycrystalline, or amorphous silicon are utilized for the above purpose.[8]

\section{PV CELL CHARACTERISTICS}

Solar Energy is Free, continuous, and Pollution-free. PV Arrays use photovoltaic conversion to generate electricity. It is a transformation of Electrical energy from photon energy from solar radiations. The PV cell is designed in such a fashion that the P-N junction of semiconductor Material, is homogenous to a diode as shown in Figure1 [9-10]

Due to impurity doped in the P-N junction, the creation of an electric field at the junction happens, which uses on one side P-doping and on the other side N-doping. indispensably, when the exposure of the cell happens to light quanta, the photon energy creates charge carriers, which were spread across the electrical field, due to which creation of a new depletion region exists between the $\mathrm{P}$ and $\mathrm{N}$ sides of the junction.[11]

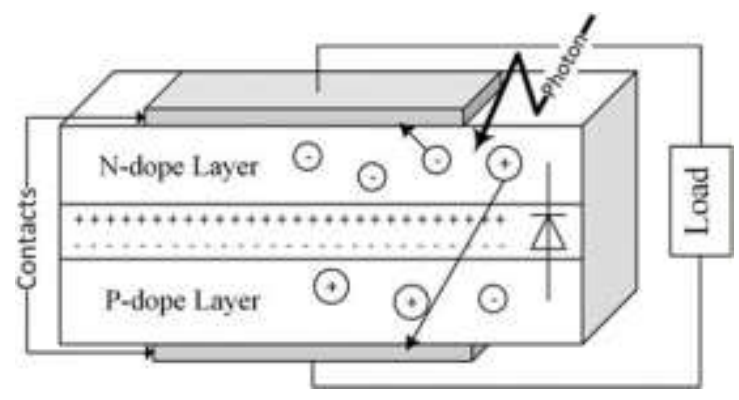

Fig.1 PV cell

As a result, a voltage is yielded across the external contacts, creating a current flow to the load as a response if the circuit is completed [25]. In PV Array the current flow is directly proportional to the intensity of luminosity of the sunlight. For the above PV cell, an Equivalent circuit is shown below which is comprehended with a current source accompanied by a parallel diode here Passenger Resistance is 
present the Series Resistance has a small value in comparison to Passenger Resistance. Here depends on various factors such as junction contacts, semiconductor material, interconnections. R_SH is Responsible to hold blemishes and impurities present in P-N junction. [12-14]

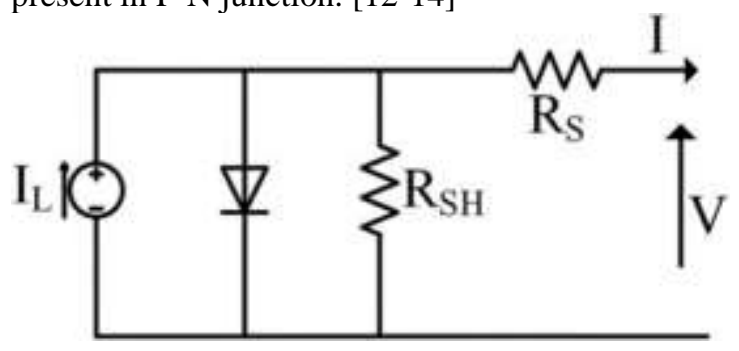

Fig.2 Equivalent Circuit of PV Array

The type of Semiconductor material used affects the performance of the PV array to a great extent. Numerous interdependent relationships are procreated for PV Array temperature problems that are used in literature which include essential environment-related variables and Parameters which are must for the conduction of experiments. [15-17] The power generated from the PV Generator (PVG) is dependent on solar shielding and favourable temperature, usually, a PV array is placed in severe climatic conditions. The temperature at which the PV conversion process operates plays a pivotal role. The electrical efficiency and the power output of a PV (photovoltaic) Array is directly Proportional to the (operating temperature).[18]

In the conventional method PV array with a direct connection to a partially shaded Array show low output power and efficiency. This paper proposes a new PV array connection method by which if an array of PV string is faulty it can be disconnected and other strings of PV array will work with the help of NPC inverter. [19-20]

In the conventional method performance of the PV Array in direct relation to operating temperature is shown. This paper searches new Probabilities for PV Array connections by which if an Array of PV string is faulty it can be disconnected and other strings of PV Array can work.[21]

\section{EFFECT OF TEMPERATURE ON ELECTRICAL EFFICIENCY IN PV ARRAY}

PV arrays are largely affected by temperature and ambiance, this effect can be calculated by using the following equation.

$$
P_{m=} I_{m} * V_{m}=(F F) I_{s c} * V_{o c}
$$

In above equation FF is fill factor, for short circuit current, $V_{O C}$ is open-circuit voltage, and here the maximum power in the PV Array of the I-V curve is given by subscript $\mathrm{m}$ in the above interdependent relationship. Both F.F. (fill factor) and O.C. (open circuit) voltage decrease considerably with temperature. Therefore, in the graph, a linear dependent relationship is observed.

$$
\begin{gathered}
\eta_{c}=\eta T_{r e f}\left[1-\beta_{R e f}\left(T_{C}-T_{R e f}\right)+\right. \\
\quad \gamma \log _{10}\left(I_{t}\right)
\end{gathered}
$$

Here $\eta T_{\text {Ref }}$ is electrical efficiency at reference temperature for Array for and solar radiations used here is $1000 \frac{\mathrm{W}}{\mathrm{m}^{2}}$.here $\beta_{\text {Ref }}$ is taken as temperature coefficient and $\mathrm{\gamma}$ is taken solar luminosity coefficient have material properties of values 0.004 K-1 and 0.12 for crystalline silica Arrays [15] The second one is normally taken as zero Evans [16] and equation 2 is reduced to

$$
\eta_{c}=\eta_{T R e f}\left[1-\beta_{R e f}\left(T_{c}-T_{R e f}\right)\right]
$$

The above equation shows the interrelationship for PV $\eta$ (electrical efficiency) Florschuetz and Evans. The value of temperature coefficient depends on $T_{R e f}$ and PV material which is given by following equation

$$
\beta_{\text {Ref }}=\frac{1}{T_{o}-T_{\text {Ref }}}
$$

Here $T_{0}$ is extreme temperature at, Garg and Agarwal [20] silicon crystalline arrays have $2700 C^{0}$ Florschuetz and Evans for many interdependent relationships the temperature of Array is replaced by $T_{N O C T}$ so the new equation becomes.

$$
\begin{array}{r}
\eta=\eta_{r e f}\left[1-\beta\left[T_{a}-T_{R e f}+\right.\right. \\
\left.\left(T_{N O C T}-T_{a}\right) \frac{I(t)}{I(t)_{N O C T}}\right]
\end{array}
$$

\section{SCENARIO OF PV POTENTIAL AROUND THE GLOBE}

A new and promising technology PV (photovoltaic) conversion energy is used for electric power generation from a renewable energy source of energy by solar luminosity. However, the PV output varies very highly concerning its various operating conditions, hence calculation of $\mathrm{PV}$ potential is a cumbersome task. In addition to that, the data provided is of a limited period. To achieve accuracy within available data is a tedious task. Generally, to calculate PV potential two methods are applied 1) Energy rating method 2) power rating method.[23] In the Power rating method, instantaneous PV power generation is pre-planned with the response to time, thereby, PV output is dependent on time and the crucial issue in this method is that it is very complex to calculate and data is required in a precise manner. 


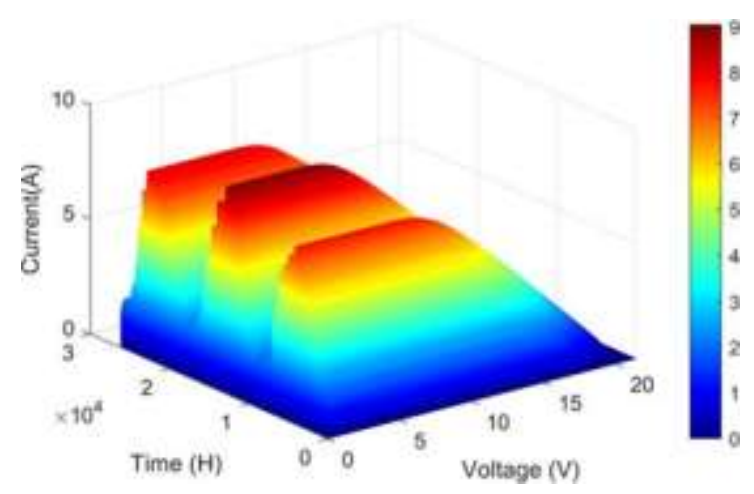

Fig.3 V-I characteristics of 3 years

Collection of Instantaneous data of ambience at global level is next to impossible therefore in no work global PV potential could be estimated in December 2016 PV solar Energy calculated was around $303 \mathrm{GW}$ around the globe.

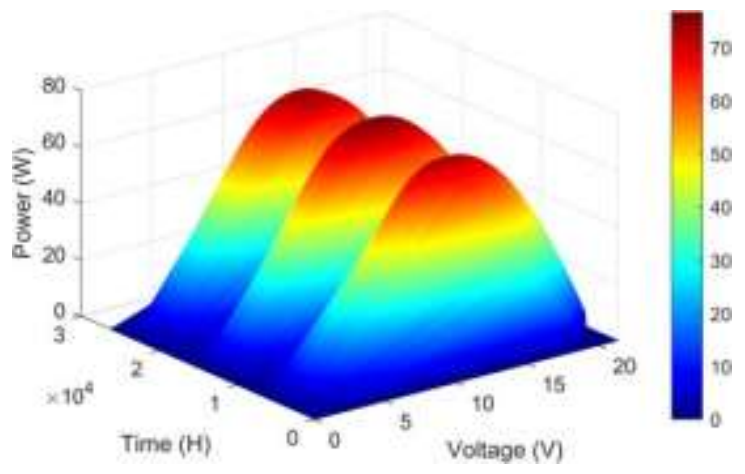

Fig.4 PV characteristics of 3 years

This work studies the effect of variations of different temperatures and harsh climatic conditions on PV Array. In this study data set of avg. sun radiations is taken hourly and daily an hourly Average temperature for $2001-2003$ is shown in figure 3 and figure 4 .
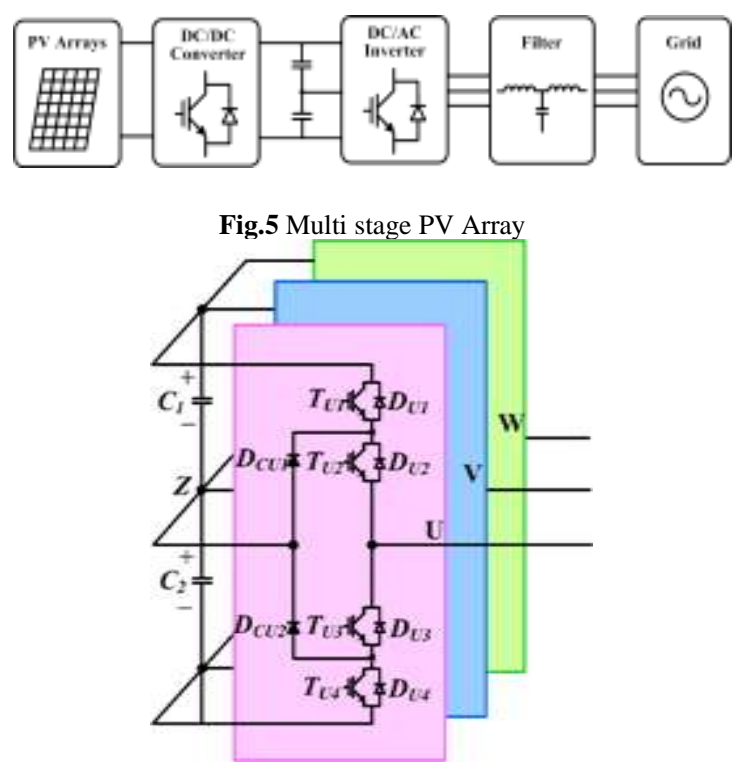

Fig.6 NPC Inverter circuit

A Multi stage grid connected PV system is shown in figure 5. PV arrays are accompanied by DC /AC PV Inverter and DC/DC Converter and grid works as an interface. Generally, the DC/DC boost converter is also used but it can be exempted as per applications [24].

One of highly desirable topology NPC inverter is comprised here because of low harmonics distortion and good efficiency. NPC Inverter are used both type of configuration 1) string type inverter configuration 2) central inverter configuration [21]

As shown in Figure 6, The NPC Inverter is comprised of four IGBT's $\left(T_{X 1}(X U, V\right.$, $\left.\mathrm{W}), T_{X 2}, T_{X 3}, T_{X 4}\right)$ four diodes $\left(D_{X 1}, D_{X 2}, D_{X 3}, D_{X 4}\right)$ and two Clamping Diodes $\left(D_{X 1}, D_{X 2}\right)$. In each connection here Same rated V-I (voltage and current) IGBT's are used.

NPC Inverter's various temperature distribution and power losses - In this area NPC inverter's different attributes of distribution such as power loss and corresponding temperature distribution is evaluated at rated power as shown in Figure 7 below.
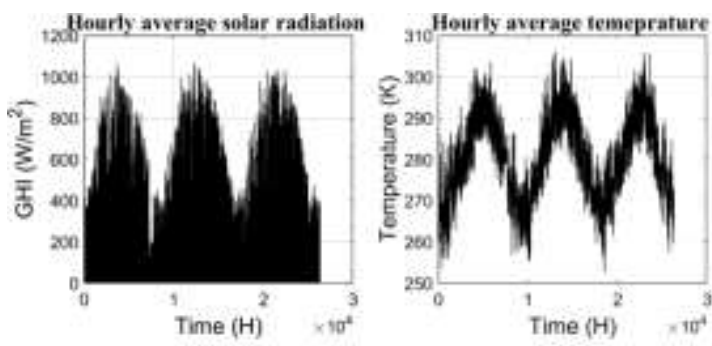

Daily average selar radiation

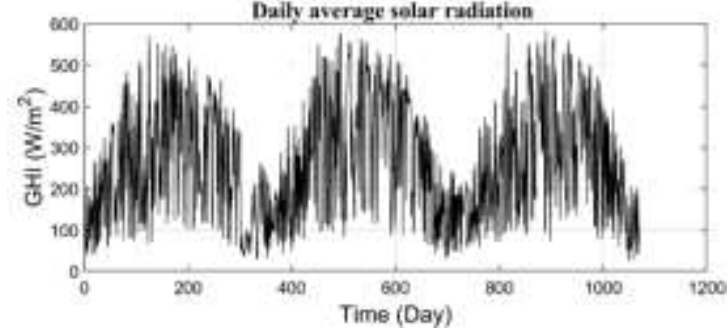

Fig.7 Variation of average solar radiation and NPC Inverter temperature according to different time.

Here PV inverter is examined with two control strategy one is conventionally used control method and other is space vector modulation method the related parameters of PV array considered is taken from [1]

It is comprehensively ensured that PV Array is always operated in safe operation mode. To make sure that the cooling system's capacity is assigned according to the junction temperature $T_{i}$ which is comprehensive to take around $70-80 \%$ of rated junction temperature $T_{M A X}$ [23]. Here Resistance $R_{t h(h-a)}$ is selected of $0.17 \mathrm{~K} / \mathrm{W}$. 
Power loss $\left(P_{\text {loss }}\right)$ of the device amounts to addition of switching loss $\left(P_{S W}\right)$ and conduction loss $\left(P_{C O N D}\right)$ as

$$
P_{\text {loss }}=P_{S w}+P_{\text {COND }}
$$

The $P_{s w}$ of the IGBT can be calculated as under

$$
P_{S W}=E_{S W} \cdot f_{S W}
$$

Here $E_{S W}$ and $f_{S W}$ comprises energy of switching and frequency for switching of the device.

The loss in conductivity is calculated by switching cycle which is calculated as under

$$
P_{C O N D}=V_{C E} \cdot I_{C E} \cdot D
$$

Here $\mathrm{V}_{\mathrm{CE}}$ is the collector -emitter voltage, $\mathrm{D}$ is duty cycle and $I_{c}$ is collector current. It can be taken into consideration that $V_{C E_{O N}}$ and $E_{S W}$ of IGBT are affected by junction temperature when power loss is accounted.

The temperature of junction can be calculated as under:

$$
\begin{gathered}
T_{(I G B T)(t)}=P_{\text {loss }(I G B T)(t)} \cdot Z_{t h(j-h)(t)}+ \\
P_{\text {loss }(\text { Module })(t)} \cdot Z_{t h\left(h^{-}-a\right)(t)}+T_{a}(4)
\end{gathered}
$$

where $P_{\text {loss }(I G B T)}=$ IGBT power loss, $Z_{t h(j-h)}=$ junction to heat-sink thermal impedance, $P_{\text {loss(Array) }}$ $=$ IGBT Array power loss, $Z_{t h(h-a)}$ heat-sink to ambient thermal impedance and $T_{a}$ favourable temperāture.[22]

_The $Z_{t h(j h)}$ of the power devices are represented by the Foster model as

$$
Z_{t h(j-h)}(t)=R_{i}\left(1-e^{\left(1-e^{-\frac{t}{T}}\right)}\right.
$$

$i=1$

here $\tau, \mathrm{R} \mathrm{C}$ and $\mathrm{i}$ shows the different surfaces of the power Array to enrich layout.

\section{CONCLUSION}

A major role in the photovoltaic conversion phenomenon is played by (Operating temperature). Electrical efficiency and power output both rely linearly upon the (operating temperature) show major decrease with increase in temperature. Numerous Interdependent relationships are formulated in this paper which is shown in literature are applied to freely mount BIPV installations, PV arrays, and PV/thermal collectors respectively. Which include numerical parameters and basic ambience variables, while they are not only material but physical attributes too.

In The energy rating method PV potential is calculated by multiplying the total solar luminosity for a particular interval of time by a performance ratio. To calculate PV potential for world scholars, prefer the energy rating method because of simple method and availability of global weather. In this study Performance ratio is also used.

PV potential's Energy rating is product of total solar luminosity in a specific interval of time to performance ratio. The energy rating method is simple and because data on global weather is not available readily. PV potential can be estimated effortlessly. performance ratio used is constant.

But Practically Constant performance ratio is not available due to various environmental conditions due to which variation in results are observed.

\section{REFERENCES}

[1] Mansour, R., Mateen Khan, M., Alsulaiman, F., \& Mansour, R. (2021). Optimizing the Solar PV Tilt Angle to Maximize the Power Output: A Case Study for Saudi Arabia. IEEE Access, 9, 15914-15928. doi: 10.1109/access.2021.3052933

[2] Driesse, A., Theristis, M., \& Stein, J. (2021). A New Photovoltaic Module Efficiency Model for Energy Prediction and Rating. IEEE Journal Of Photovoltaics, 11(2), 527-534. doi: 10.1109/jphotov.2020.3045677

[3] Choi, U., 2020. Study on Effect of Installation Location on Lifetime of PV Inverter and DC-to-AC Ratio. IEEE Access, 8, pp.86003-86011.

[4] Babu, T., Yousri, D., \& Balasubramanian, K. (2020). Photovoltaic Array Reconfiguration System for Maximizing the Harvested Power Using Population-Based Algorithms. IEEE Access, 8, 109608-109624.

[5] Chauhan, Y., Rana, V., \& Ansari, M. (2020). Investigation of partial shading effect on PV array configuration. International Journal Of Digital Signals And Smart Systems, 4(1/2/3), 184

[6] Luna-Rubio, R., Trejo-Perea, M., Vargas-Vázquez, D., \& Ríos-Moreno, G. (2012). Optimal sizing of renewable hybrids energy systems: A review of methodologies. Solar Energy, 86(4), 1077-1088.

[7] R.Luna-Rubio,M.Trejo-Perea, D.VargasV'azquez, andG.R'1os-Moreno, "Optimal sizing of renewable hybrids energy systems: a review of methodologies," Solar Energy, vol. 86, no. 4, pp. 10771088, 2012.

[8] S. Shehadeh, H. Aly, and M. El-Hawary, "An overview of inverter topologies for photovoltaic electrical energy," Presented at the 2013 IEEE Electrical Power \&Energy Conference, Halifax, NS, Canada, pp. 1-8, 21-23 August 2013. IEEE.

[9] S. Ghosh and I. Dincer, "Development and analysis of a new integrated solar-wind-geothermal energy system," Solar Energy, vol. 107, pp. 728-745, 2014.

[10] European Renewable Energy Council, Renewable Energy Scenario to 2040. 2012.Brussels.

[11] J. Carrasco et al., "Power-electronic systems for the grid integration of renewable energy sources: a survey," IEEE Trans. Ind. Electron., vol. 53, no. 4, pp. 1002-1016, 2006.

[12] Munir, S., \& Li, Y. (2013). Residential Distribution System Harmonic Compensation Using PV Interfacing Inverter. IEEE Transactions On Smart Grid, 4(2), 816-827. doi: 10.1109/tsg.2013.2238262

[13] Masoum, M., \& Fuchs, E. (2015). Power quality in power systems and electrical machines. Amsterdam: Academic Press/Elsevier.

[14] Beser, E., Arifoglu, B., Camur, S., \& Beser, E. (2010). A grid-connected photovoltaic power conversion system with single-phase multilevel inverter. Solar Energy, 84(12), 2056-2067. doi: 10.1016/j.solener.2010.09.011

[15] Patsalides, M., Stavrou, A., Efthymiou, V., \& Georghiou, G. (2012). Towards the establishment of maximum PV generation limits due to power quality constraints. International Journal Of Electrical Power \& Energy Systems, 42(1), 285-298. doi: 10.1016/j.ijepes.2012.03.043

[16] Žnidarec, M., Klaić, Z., Šljivac, D., \& Dumnić, B. (2019). Harmonic Distortion Prediction Model of a Grid-Tie Photovoltaic Inverter Using an Artificial Neural Network. Energies, 12(5), 790. doi: 10.3390/en12050790

[17] Jafarian, H., Kim, N., \& Parkhideh, B. (2018). Decentralized Control Strategy for AC-Stacked PV Inverter Architecture Under Grid Background Harmonics. IEEE 
Journal Of Emerging And Selected Topics In Power Electronics, 6(1), 84-93. doi: 10.1109/jestpe.2017.2773079

[18] Tavakoli Bina, M., \& Pashajavid, E. (2009). An efficient procedure to design passive LCL-filters for active power filters. Electric Power Systems Research, 79(4), 606-614 doi: 10.1016/j.epsr.2008.08.014

[19] Maheshwari, N., \& Chandrasekaran, M. (2019). Harmonic Analysis of Photovoltaic-Fed Symmetric Multilevel Inverter using Modified Artificial Neural Network. Applied Mathematics \& Information Sciences, 13(1), 105-113. doi: 10.18576/amis/130114

[20] Kjaer, S., Pedersen, J., \& Blaabjerg, F. (2005). A Review of Single-Phase Grid-Connected Inverters for Photovoltaic Modules. IEEE Transactions On Industry Applications, 41(5), 1292-1306. doi: 10.1109/tia.2005.853371

[21] Quan Li, \& Wolfs, P. (2008). A Review of the Single Phase Photovoltaic Module Integrated Converter Topologies With Three Different DC Link Configurations. IEEE Transactions On Power Electronics, 23(3), 1320-1333. doi: 10.1109/tpel.2008.920883

[22] Kouro, S., Leon, J., Vinnikov, D., \& Franquelo, L. (2015). Grid-Connected Photovoltaic Systems: An Overview of Recent Research and Emerging PV Converter Technology. IEEE Industrial Electronics Magazine, 9(1), 47-61. doi: 10.1109/mie.2014.2376976

[23] Schweizer, M., Friedli, T., \& Kolar, J. (2013). Comparative Evaluation of Advanced Three-Phase Three-Level Inverter/Converter Topologies Against Two-Level Systems. IEEE Transactions On Industrial Electronics, 60(12), 5515 5527. doi: 10.1109/tie.2012.2233698

[24] Li, Z., Zhang, Z., \& Davey, K. (2015). Estimating Geographical PV Potential Using LiDAR Data for Buildings in Downtown San Francisco. Transactions In GIS, 19(6), 930-963. doi: 10.1111/tgis.12140

[25] Kawajiri, K., Oozeki, T., \& Genchi, Y. (2011). Effect of Temperature on PV Potential in the World. Environmental Science \& Technology, 45(20), 9030-9035. doi: 10.1021/es200635x. 